\title{
Creating Object-Based Learning for the Anthropocene: A Critical Reflection
}

\author{
Becky Alexis-Martin, \\ Manchester Metropolitan University, United Kingdom
}

\begin{abstract}
The Anthropocene is the human age. Its undeniable significance has been ascribed across disciplines from geology, to cultural studies, to fine art. Through reflective analysis, this paper explores the role and significance of creative practice, the found object, and the use of object-based adventures in teaching the Anthropocene. It also considers the role of virtual object-based learning in a digital age through a "Gallery of Late Humanity", through the reflexive lens of a lecturer who teaches both environmental sciences and cultural geography. These methods successfully encouraged learning across and beyond the disciplinary boundaries of geography and fine art, providing creative re-imaginings, visualisations and understandings of the Anthropocene. These approaches illustrate how the quotidian materialities of home can be reconfigured as a field site for the late Anthropocene.
\end{abstract}

Keywords: Anthropocene; Object-based learning; Multimedia; Visual; Interdisciplinary 


\section{An introduction to teaching the Anthropocene}

Geologists have described the Anthropocene as the "...appearance and increased abundance of anthropogenic deposits... and biotic turnover" (Lewis and Maslin 2015: 171), providing empirical insight into our human creations and widespread destruction (Waters et al 2014). Conversely, the social sciences focus on teaching the cultural and socio-environmental implications of humanity; which span from climate change and nuclear warfare, to mass-extinction and our own self-oppression (Greenwood 2014). However, there is still a distinct ontological divide between those in physical sciences and cultural studies, which has led to the adaptation of Anthropocene notions to fit broader cultural and critical understandings. Further Anthropocene constructions include the Capitalocene, as a human age of global capitalism; and the Chthulucene, which is named not after H.P. Lovecraft's monster - but in homage to the more-thanhuman, other-than-human, inhuman, and beyond (Haraway 2015). All of these are dependent upon scale, velocity, "synchronicity, and complexity", in providing different insights into their specific notions of the age of humanity (Haraway 2015:159). However, would an Anthropocene by any other name be less intriguing or consequential? What is inarguable is that, as the most dominant species on Earth, we have had a tremendous impact. From the depths of our ocean to the space junk that orbits our planet, these impacts have left object-based traces across our landscapes.

When I begin my teaching on Anthropocene culture, regardless of discipline, I start with the declaration that we are all human - but what is "we"? and what even, is "human"? Humans are not alone in the animal kingdom as teachers and learners, and this seems like an interesting place to begin my interdisciplinary object-based teaching exploration. The Anthropocene is simply the age of humanity, the timescale whereby humans have dwelled on Earth alongside more-than-human species. For geology and environmental science students, learning the Anthropocene is often inherently objectbased and material by nature. It is undertaken through the physical sampling and analysis of anthropogenic materials taken from our environmental deposits, from oceanic micro-plastics to artificial radionuclides, or the "techno-fossils" of landfill detritus (Zalasiewicz et al 2016). These traces are then explored through the anthropogenic tactility of the laboratory. This learning is an essentially anthropocentric process, with a focus upon our ability to understand the chemical or physical object, in order to comprehend - and perhaps solve - the environmental challenges posed by humanity.

Within the social sciences and humanities, an object-based learning approach has been less common, beyond the domains of material culture and museum studies (Chatterjee, and Hannan 2016). While visual representation is important to human geography, visual information is prioritised and conveyed to students through visual media such as film and photography, rather than by object-based approaches (Driver 2003). For example, a place-based understanding for a case study may be constructed through the depiction of current affairs media (Conover and Miller 2014); or multimedia podcasts and other vernacular digital technologies may be used to give students a taste of place and time (Cannon 2018). Field trips often focus upon environmental observation and human interaction, rather than the interactive materialities of specific objects that

International Journal of Management and Applied Research, 2020, Vol. 7, No. 3 
construct the socio-environmental assemblage (Robinson, 2018). From my perspective as a cultural geographer, the Anthropocene is a cultural, environmental and technoscientific phenomenon - and its constituent human objects and materialities offer important sensory insights into what it means to be human.

\section{Object-based learning}

Object-based learning (OBL) encourages multi-sensory and experiential critical understandings that are imbued with materiality (Chatterjee and Hannan 2015). OBL is tactile, vivid and sometimes even smelly, supporting educators to create a memorable and diverse learning experience for their participants. It has been successfully applied across educational settings from Egyptology courses to zoology museums, to support experiential learning and visitor empowerment (Cain 2010; Janssen et al., 2020; Nicholl and Davies 2019). Object-based learning is entangled with, and impossible to undertake without including Experiential Learning Theory (ELT), an approach that provides a holistic model of the learning process, and that embraces practical experiences (Kolb et. al. 2001; Moon, 2013). For this reason, it is a powerful and dynamic way to learn.

Importantly, ELT can be inclusive for those with learning differences, as it requires searching self-expression and tactility, rather traditional academic skills such as note taking. Here, I describe how I have implemented object-based learning across my teaching. I explore two scenarios where object-based learning has been essential to my pedagogy, and where it has contributed substantial enrichments to my participant's learning. The first "found objects" scenario considers encouraging the discovery of found Anthropocene materialities and their traces, during an interdisciplinary field day across the city of Manchester, UK; the second "object adventure" offers hypothetical adaptations for digital object-based Anthropocene learning.

\section{Found object adventuring}

I have elucidated within the introduction how the Anthropocene can be culturally and environmentally bounded and defined by the anthropogenic object. This cultural encounter with the Anthropocene offers students an opportunity to engage with the materialities of the city of Manchester, UK; and to gain insights into deep time and the ubiquity of humanity's detritus. Here, I explore a co-produced collaborative teaching event, with Dr David Griffiths in the Art School. This teaching intervention was intended for BA Human Geography students and MA Art-Science students. The triggering rationale for this approach is a need to introduce and embed concepts pertaining to the Anthropocene and material culture within both student communities, in a memorable and accessible format. It also provides an opportunity for students to exchange skills and introduce themselves to new experiential practices across cultural and creative studies. As a cultural geographer and an artist, we respectively have different pedagogies and practices that we applied. I was personally responsible for preparing introductory lecture materials to inform initial cultural and social insights into the Anthropocene. I also provided psychogeographical prompts for places to explore across the city that are particularly rich in Anthropocene traces and ephemera, including Pomona Island and Manchester Mayfield Station, as shown in Figure 1.

International Journal of Management and Applied Research, 2020, Vol. 7, No. 3 
Figure 1: Manchester Mayfield is a former Edwardian railway station in Manchester, England, on the south side of Fairfield Street next to Manchester Piccadilly Station

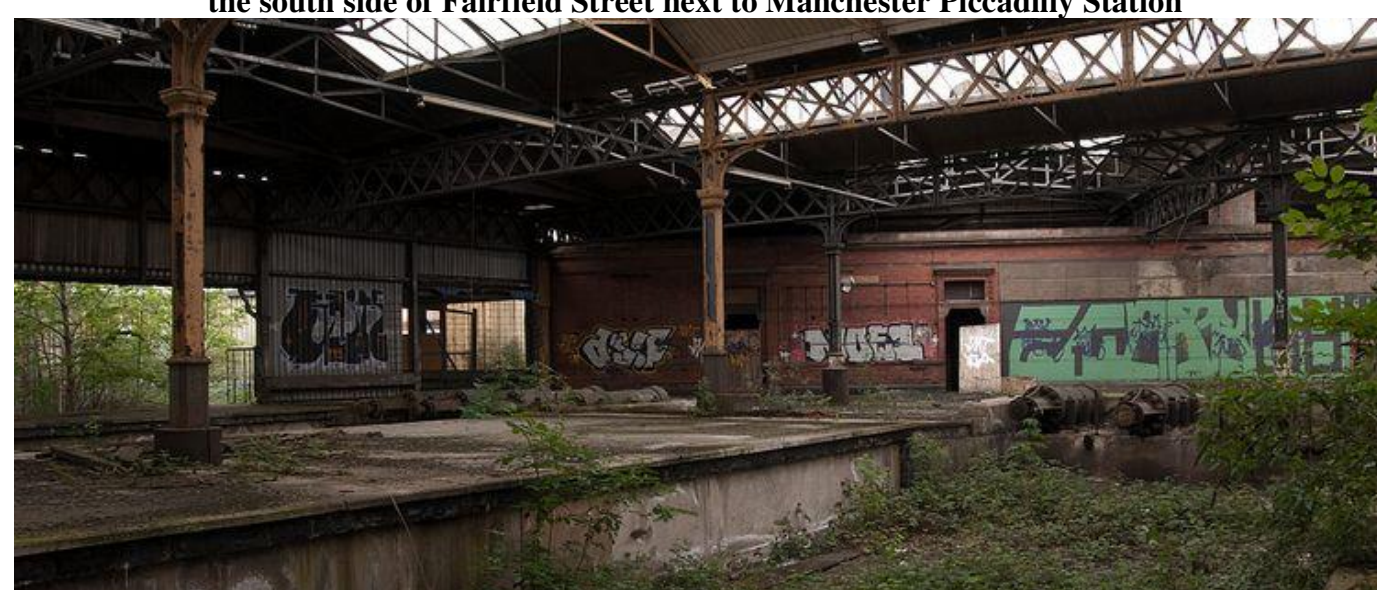

Source: Warehouse Project (2019)

For our students, moving through the city and associated psychogeographical investigation formed an important part of this aesthetic practice, and provided a critical tool for the discovery and collection of Anthropocene objects (Bassett 2004). The need for Anthropocene objects to be discovered by the students themselves gave autonomy to their object-based learning. Both artists and human geographers must view the world through a cultural lens. By merging the diffusely experiential pedagogy of creative arts with the theoretical framework of cultural geography, we created a new hybrid learning experience for students, which offered something fresh, multi-sensory, highly visual, and engaging. Within the lecture theatre, students were given insights into the meaning of the Anthropocene through audio-visual multimedia. This included a short film of Pomona Island that they watched beforehand, a still of which is shown in Figure 2. The discarded materialities of city life are clearly evident within Figures 1 and 2, but experiential learning theory requires direct engagement with the abandoned objects that humanity has left behind, and their further consideration in the context of the Anthropocene. Are these puzzles for future archaeologists - or the first stage of a latent anthropogenic environmental disaster? What sights, smells and tastes accompany the dereliction of this industrial wasteland?

Figure 2: A screenshot from a short film about Pomona Island as a derelict space. Visual media and ambient sound is used to create atmosphere and understanding of the Anthropocene before

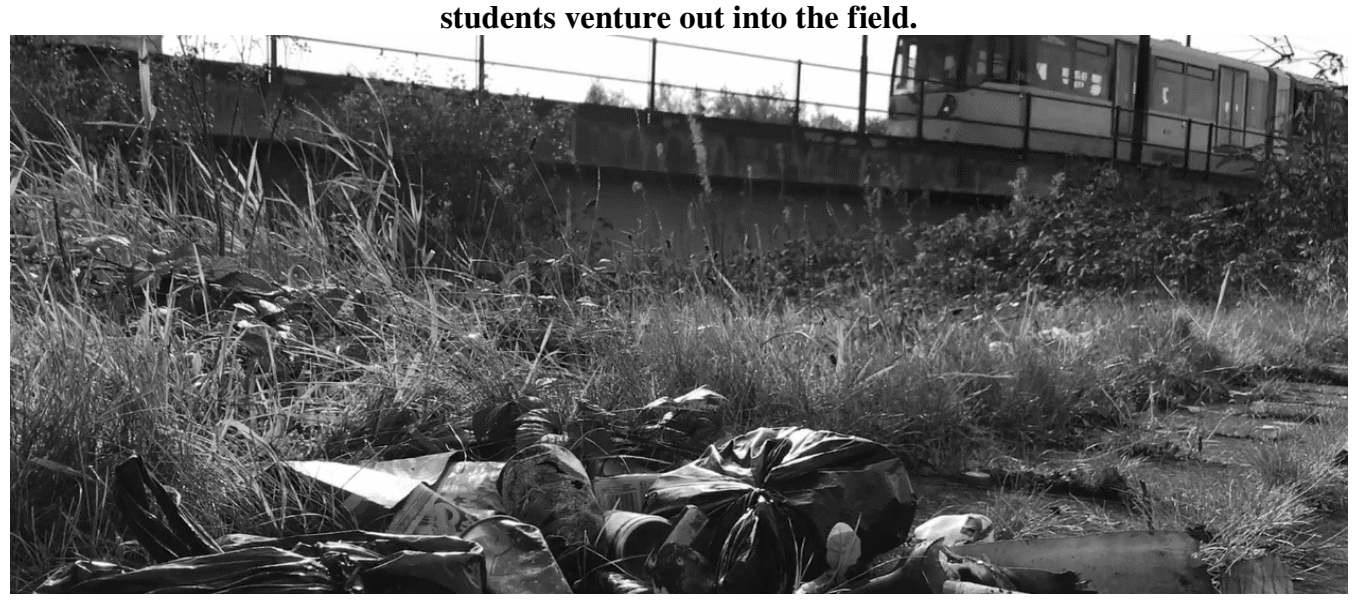

International Journal of Management and Applied Research, 2020, Vol. 7, No. 3 
The students visualised places where Anthropocene objects could be found. They were then encouraged to safely and legally explore Manchester; with care, support and solidarity for themselves and their fellow students (Mott and Roberts 2014). The students returned later with their Anthropocene found objects, after undertaking various creative visual methods. These included etchings, rubbings, psychocartography, photography, film and sound; to record their textural experience of Manchester's discards, its industrial legacy, and its (im)permanence through objectbased learning (Prieto 2016; Chatterjee and Hannan 2016).

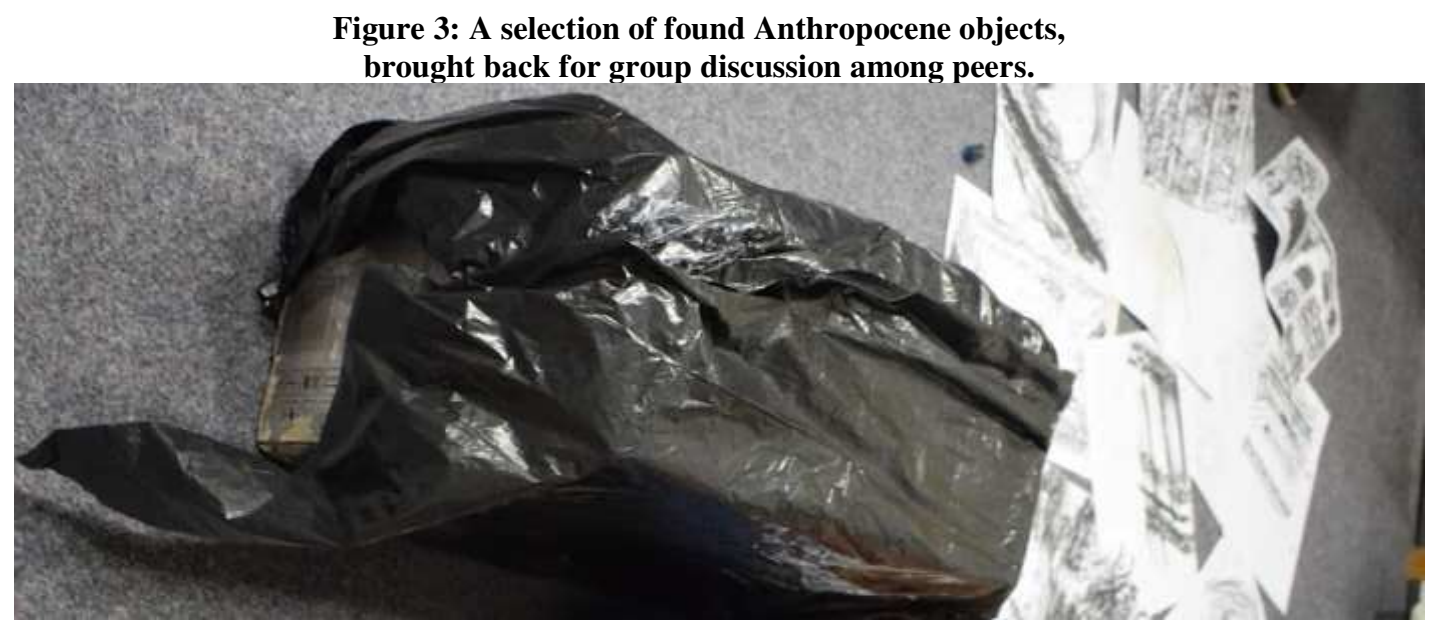

We encouraged our students to think creatively and consider liminal spaces, hidden things, and the significance of scale to their Anthropocene encounters. The fieldwork produced some exciting objects. Figure 3 depicts some Anthropocene found objects that were brought back to be discussed by students. These ranged from sketches and etchings, to plastic bin bags and aluminium ring-pulls. It was evident from the discussions that this had been a rewarding exercise, encouraging creative approaches. Some initially challenges arose due to the complexity of the topic and a lack of experience with the idea. It was clear that this was due in part to differences in background knowledge and academic vocabulary between students of geography and students of fine art. Close, dynamic collaboration between myself and Dr Griffiths was therefore crucial for addressing these challenges to ensure that students could have these new ideas delivered in the context and language of their own discipline. Many students thrived in this cross-discipline setting, enjoying the change in learning style and subject.

\section{The Gallery of Late Humanity}

The sensory experience of object-based learning can present major limitations pertaining to (im)mobilities for people with disabilities. Notably, field-trip based object-seeking learning can institute challenges relating to differently-abled bodily practices, timings and spaces (Hansen and Philo 2007). Here, I explore participatory

International Journal of Management and Applied Research, 2020, Vol. 7, No. 3 
and inclusive alternatives to traditional and masculinist cultural geography fieldwork practices (Mott and Roberts 2014).

This digitally mediated object-based learning approach is also significant in light of anticipated changes to learning due to the COVID-19 pandemic. In spring 2020, many countries, including the UK, restricted gatherings and enforced social distancing in order to reduce the spread of COVID-19. This has had myriad impacts on teaching, learning, and academic research. One of the significant effects of these restrictions is the inability to safely undertake tactile, visual, exploratory, interpersonal teaching methods, as well as a new emphasis on remote learning. However, a creative approach can be used to bring the key benefits of experiential learning (e.g. the Anthropocene Field Day) into students' homes and connected through digital methods.

I have entitled this approach the "Gallery of Late Humanity", as it taps into existing digital practices pertaining to the vernacular of shared quotidian online materialities. Across social media, these culturally and digitally mediated object-based photographic sharing practices include "shelfies" of book collections (Bollmer and Guinness 2017); potted plants, and "tiny homes" (Gretzel and Hardy 2019). The sharing practices around these objects are complex, but they have symbolic value as particular cultural signifiers that provide insights into the (curated) life of the poster. The "Gallery of Late Humanity" uses this trope to visually explore the Anthropocene, through the descriptive curation of objects that already exist within the participant's own home.

For example, we can gain insights into ancient societies from the shards of pottery that they have left behind (Erlandson and Braje 2013). A collection of Wade Whimsy animal figurines will not biodegrade with ease, but will instead become conglomerate, embedded within sediment for future civilisations. They could become xenoliths within a future stratigraphy made of colourful glazed pottery, or mud-larked members of the post-Anthropocene, whoever and whatever they may be. They have a smooth, cool exterior and were cast in the 1980s potteries of Stoke-on-Trent, UK. They have a past embedded in post-industrial UK, a present as a collection of kitsch animal-like objects, and an unknown future.

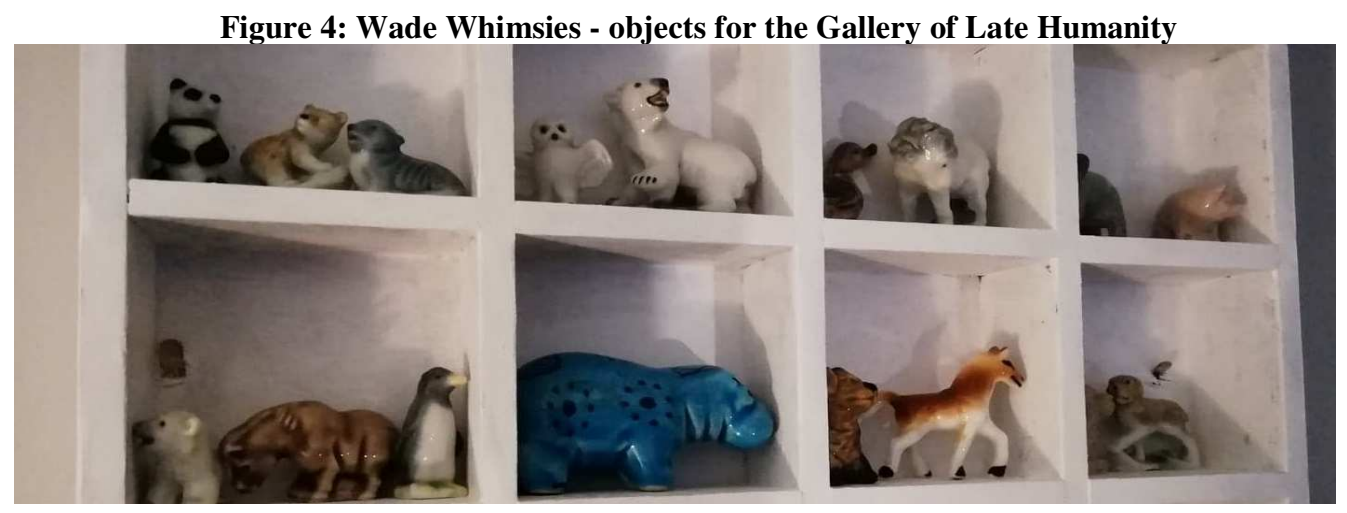

Discussions with students have highlighted how engaging this object auditing and contemplation process could be when offered as a learning experience to consider the

International Journal of Management and Applied Research, 2020, Vol. 7, No. 3 
(im)materiality of being human, and the impacts of late capitalism on the home. Students responded positively to these plans, highlighting how this intimate and domestic lens on the Anthropocene offers them a way to undertake and co-create creative cultural research, while developing a new understanding of their home. These individual solitary psychogeographies will meld together online with the contributions of other participants, to create the Gallery of Late Humanity. This offers a virtual space for each object to be explored by each individual in the context of Anthropocene traits such as obsolescence, degeneration or permanence (Latour 2017; Bauer and Ellis 2018). Each object's significance and meaning can be unpacked, exhibited and described within the context of an unknown human future, across the gallery. Despite the absence of shared tactile materialities and searching experiences, the virtual gallery provides a new space for participatory object-based learning (Gretzel and Hardy, 2019). Through visual object-based learning, we can reconfigure the home as a potential field site of the late Anthropocene.

\section{Conclusion}

To conclude, I have investigated the usefulness of object-based learning to convey interdisciplinary understandings of the Anthropocene, through reflection of my personal experiences of experiential teaching for found object fieldwork. Students responded positively to these approaches, taking the opportunity to engage in a change of environment and learning style. In particular, the Anthropocene field day allowed students to engage across the disciplinary boundaries of geography and fine art, which resulted in positive learning experiences for both groups. The parameters of these approaches must be fine-tuned, to ensure that tasks are set at the appropriate difficulty and that goals are achieved with and without direct supervision.

I have also considered the consequences of lockdown (im)mobilities to tactile and visual learning, and I have explored the role of culturally mediated digital media in future teaching, such as a "Gallery of Late Humanity", to showcase quotidian and domestic Anthropocene objects. Many questions remain around the interdisciplinary benefits of object-based learning, and the further opportunities are available to develop this practice through physical digital mediums. From making models specifically for object-based learning (Hancock, 2015), to the value of virtual reality technologies for visualising hypothetical future Anthropocene catastrophe, there is still much left for educators to consider and explore.

\section{References}

1. Bassett, K., (2004), "Walking as an aesthetic practice and a critical tool: Some psychogeographic experiments", Journal of Geography in Higher Education, Vol. 28, No. 3, pp.397-410. https://doi.org/10.1080/0309826042000286965

2. Bauer, A.M. and Ellis, E.C., (2018), "The Anthropocene Divide: Obscuring Understanding of Social-Environmental Change", Current Anthropology, Vol. 59, No. 2, pp. 209-227. https://doi.org/10.1086/697198

3. Bollmer, G. and Guinness, K. (2017), "Phenomenology for the Selfie", Cultural Politics, Vol. 13, No. 2, pp.156-176. https://doi.org/10.1215/17432197-4129113

International Journal of Management and Applied Research, 2020, Vol. 7, No. 3 
4. Cain, J. (2010), "Practical Concerns when Implementing Object-based Teaching in Higher Education", University Museums and Collections Journal, Vol. 3, pp197203. https://doi.org/10.18452/8701

5. Cannon, M. (2018), Digital media in education: Teaching, learning and literacy practices with young learners. Cham: Springer International Publishing. https://doi.org/10.1007/978-3-319-78304-8

6. Chatterjee, H.J. and Hannan, L. (2016), Engaging the senses: object-based learning in higher education. Surrey: Ashgate.

7. Conover, G.D. and Miller, J.C. (2014), "Teaching human geography through places in the media: An exploration of critical geographic pedagogy online", Journal of Geography, Vol. 113, No. 2, pp.85-96. https://doi.org/10.1080/00221341.2013.846396

8. Driver, F. (2003), “On geography as a visual discipline”, Antipode, Vol. 35, No. 2, pp.227-231. https://doi.org/10.1111/1467-8330.00319

9. Erlandson, J.M. and Braje, T.J. (2013), "Archeology and the Anthropocene", Anthropocene, Vol. 4, pp.1-7. https://doi.org/10.1016/j.ancene.2014.05.003

10. Greenwood, D.A. (2014), "Culture, environment, and education in the Anthropocene", In: Assessing schools for generation $R$ (Responsibility), Dordrecht: Springer, pp. 279-292. https://doi.org/10.1007/978-94-007-2748-9_20

11. Gretzel, U. and Hardy, A. (2019), “\#VanLife: Materiality, Makeovers and Mobility amongst Digital Nomads", E-review of Tourism Research, Vol. 16, No. 2/3, pp.1-9.

12. Hancock, M. (2015), "Museums and 3D Printing: More Than a Workshop Novelty, Connecting to Collections and the Classroom", Bulletin of the Association for Information Science and Technology, Vol. 42, No. 1, pp. 32-35. https://doi.org/10.1002/bul2.2015.1720420110

13. Hansen, N. and Philo, C., (2007), "The normality of doing things differently: bodies, spaces and disability geography", Tijdschrift voor Economische en Sociale Geografie (Journal of Economic and Social Geography), Vol. 98, No. 4, pp.493506. https://doi.org/10.1111/j.1467-9663.2007.00417.x

14. Haraway, D. (2015), “Anthropocene, capitalocene, plantationocene, chthulucene: Making kin”, Environmental humanities, Vol. 6, No. 1, pp.159-165. https://doi.org/10.1215/22011919-3615934

15. Janssen, R.; McNamara, L.; Bloxham, C.; Farrington, C.; Harman, S. and Nuttgens, J. (2020), "Empowered by experiential Egyptology and object-based learning", In: Mawani, S. and Mukadam, A. A. (Eds), Student empowerment in Higher Education. Reflecting on teaching practice and learner engagement, Volume 2, Berlin: Logos Verlag Berlin GmbH, pp.275 - 294

16. Kolb, D.A., Boyatzis, R.E. and Mainemelis, C. (2001), "Experiential learning theory: Previous research and new directions", in: Sternberg, R. J. and Zhang, L. (eds), Perspectives on Thinking, Learning, and Cognitive Styles, New York: Routledge, pp. 227-248. https://doi.org/10.4324/9781410605986-9

International Journal of Management and Applied Research, 2020, Vol. 7, No. 3 
17. Latour, B. (2017), "Anthropology at the time of the Anthropocene: a personal view of what is to be studied", In: Brightman M., Lewis J. (eds), The Anthropology of Sustainability. Palgrave Studies in Anthropology of Sustainability. New York: Palgrave Macmillan. https://doi.org/10.1057/978-1-137-56636-2_2

18. Lewis, S.L. and Maslin, M.A. (2015), "Defining the Anthropocene", Nature, Vol. 519, pp.171-180.

19. Moon, J.A. (2013), A handbook of reflective and experiential learning: Theory and practice. London: Routledge. https://doi.org/10.4324/9780203416150

20. Mott, C. and Roberts, S.M. (2014), "Not everyone has (the) balls: Urban exploration and the persistence of masculinist geography", Antipode, Vol. 46, No. 1, pp.229-245. https://doi.org/10.1111/anti.12033

21. Nicholl, J. and Davies, P. (2019), "Participating in an Object-Based Learning Project to Support the Teaching and Learning of Biological Evolution: A Case Study at the Grant Museum of Zoology", In: Harms U. and Reiss M. (eds), Evolution Education Re-considered, Cham: Springer, pp. 307-330. https://doi.org/10.1007/978-3-030-14698-6_17

22. Prieto, E., (2016), "Informal Urbanism and the Hard Question of the Anthropocene", Journal of West Indian Literature, Vol. 24, No. 2, pp.46-62.

23. Robinson, P.A. (2018), "Learning spaces in the countryside: university students and the Harper assemblage", Area, Vol. 50, No. 2, pp.274-282. https://doi.org/10.1111/area.12379

24. Warehouse Project (2019), The History of Mayfield. Available from: https://www.thewarehouseproject.com/blogs/the-history-of-mayfield [Accessed $20^{\text {th }}$ June 2020].

25. Waters, C.N., Zalasiewicz, J.A., Williams, M., Ellis, M.A. and Snelling, A.M., (2014), A stratigraphical basis for the Anthropocene?, London: Geological Society, Vol. 395, pp.1-21. https://doi.org/10.1144/SP395.18

International Journal of Management and Applied Research, 2020, Vol. 7, No. 3 